Ann. Parasitol. Hum. Comp., $1990,65, \mathrm{n}^{\circ} 4,183-187$.

Mémoire.
Key-words: Diplostomum pseudospathaceum. Daughter sporocyst. Biogenic amines. TEM.

Mots-clés : Diplostomum pseudospathaceum. Sporocyste-fils. Amines biogènes. Ultrastructure.

\title{
HISTOFLUORESCENT AND ULTRASTRUCTURAL DEMONSTRATION OF BIOGENIC AMINES IN DAUGHTER SPOROCYST OF DIPLOSTOMUM PSEUDOSPATHACEUM NIEWIADOMSKA, 1984 (DIGENEA)
}

\author{
A. CZUBAJ*, K. NIEWIADOMSKA**
}

\begin{abstract}
SUMMARY
The aminergic neurons in D. pseudospathaceum daughter sporocysts were studied by fluorescence histochemistry and electron microscopy. Green fluorescence showing the presence of catecholamines was present in the central and peripheral nervous systems.

Ultrastructurally different types of vesicles were identified on the basis of their size and morphology. Their possible function was discussed.

RÉSUMÉ : Mise en évidence ultrastructurale et par histofluorescence des amines biogènes dans le sporocyste-fils de Diplostomum pseudopathaceum Niewiadomska, 1984 (Digenea).

Les neurones aminergiques du sporocyste-fils de Diplostomum pseudospathaceum ont été étudiés par des techniques d'histochimie fluorescente et de microscopie électronique. Une fluorescence verte

observée dans le système nerveux central et périphérique indique la présence de catécholamines. Trois types de vésicules diffèrent par leur morphologie et par leur taille. Leur fonction est discutée.
\end{abstract}

\section{INTRODUCTION}

The neuronal mediators (acetylcholine, biogenic amines and neuropeptides) have been detected in the nervous systems of many digenean species. The distribution of AChE activity was used in the investigation of the morphology of the nervous system, first of all, in adults, but only rarely in cercariae and metacercariae. Some papers deal only with the nervous system morphology of the sporocyst generation (DiConza and Basch, 1975; Théron and Fournier, 1982; Matthews, 1980 ; Choubisa, 1989 ; and Niewiadomska and Moczoń, 1990). Numerous studies demonstrate the occurrence and distribution of biogenic amines mainly in the hermaphrodite generations, especially of Schistosoma mansoni and S. japonicum (Chou et al., 1972; Machado et al., 1972) and Fasciola hepatica (Bennet and Gianutsos, 1977; Shishov et al., 1987; Fairweather et al., 1987). There are also some studies on the cercariae of different species (e. g. Nezlin and Rybakov, 1988) and the rediae of Echinostomidae and $F$. hepatica (Shishov and Kanev, 1986; Shishov et al., 1987) but no observations were

* Department of Cytology, University of Warsaw, Krakowskie Przedmieście 26/28, 00-927/1 Warsaw, Poland.

** Witold Stefański Institute of Parasitology, Polish Academy of Sciences, ul. Pasteura 3, S. p. 153, 00-973 Warsaw, Poland.

Accepté le : 25 juillet 1990. made on the daughter sporocysts. The aim of this study is to demonstrate the biogenic amines in the nervous system of the daughter sporocyst of Diplostomum pseudospathaceum Niewiadomska, 1984 to complete the investigations of Niewiadomska and Moczoń (1990) on AChE activity in this generation.

\section{MATERIALS AND METHODS}

Daughter sporocysts of $D$. pseudopathaceum were removed from naturally infected Lymnaea stagnalis L.

\section{Histofluorescence}

For histofluorescence of biogenic amines a modified glyoxalic acid technique (SPG method after De la Torre and Surgeon, 1976) was used. About 50 living fragments (anterior, middle ad posterior) of long filiform sporocysts were dipped three time for $1 \mathrm{sec}$ in glyoxylic acid solution $\left(20-22^{\circ} \mathrm{C}\right)$, dried in cool air on microscopic slides for $5-20 \mathrm{~min}$, reacted in an oven at $80^{\circ} \mathrm{C}$ for $5 \mathrm{~min}$, mounted in paraffin oil or Entallan, coverslipped and placed at a hot plate $\left(80^{\circ} \mathrm{C}\right)$ for $90 \mathrm{sec}$. The fluorescence specificity was tested by pretreatment with reserpine $\left(10^{-4} \% / 24 \mathrm{~h}\right)$ to deplete monoamines from neurons (Fuxe, 1965). A histochemical test with 0.01 sodium borohydride $\left(\mathrm{NaBH}_{4}\right.$ in $95 \%$ isopropanol for the reduction of fluorephores (Corrodi et al., 1964) was also used as well as distilled water causing disappearance of specific fluorescence of catecholamines and 5-HT dihydroderivatives. Specimens were studied with an incident fluorescence microscope Jena-Med (Carl Zeiss) equipped with light pressure mercury lamps (Osram 
HBO $200 \mathrm{~W}$ ). The filters used were: exciting filter (max. ex. 400-410 nm) and yellow barrier filter (with high absorbtion below $480 \mathrm{~nm}$ ). Photo micrographs were taken with ORWO Mikroaufnahmefilm MA-8.

\section{Ultrastructure}

Sporocysts were treated routinely for electron microscope investigations (see Czubaj and Niewiadomska, 1988). Thin sections were cut on a LKB Ultratome III and viewed with a Jeol $100 \mathrm{~B}$ electron microscope.

\section{RESULTS}

\section{Histofluorescence}

The SPG method causing green fluorescence of the nervous system of $D$. pseudospathaceum daughter sporocysts
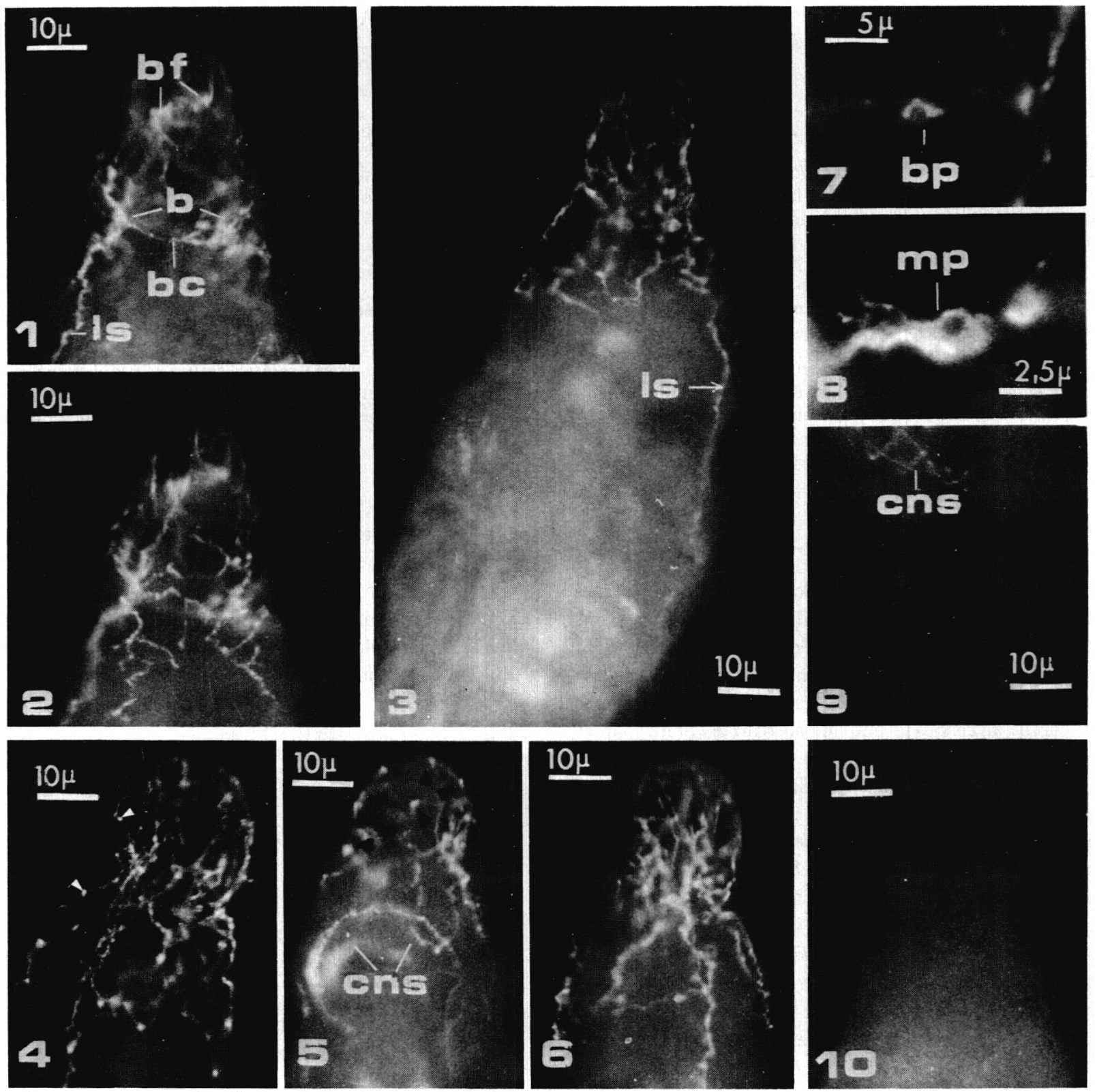

Figs. 1-10. - Monoamine fluorescence in daughter sporocyst of Diplostomum pseudospathaceum. Fig. 1. Anterior tip showing central nervous system. Fig. 2. The brain of the same specimen of different focus. The peripheral net is also visible. Fig. 3. Other specimen showing the irregular nerve net on the anterior body tip. Note the lateral strand (arrow) extending further than the net. Figs. 4-6. Different patterns of the nervous net in various specimens. Note the fluorescent endings below the body surface (arrowheads). Fig. 7 . Bipolar nerve cell (enlarged section of fig. 6). Fig. 8. Multipolar nerve cell in peripheral nervous net. Fig. 9. Posterior end of the sporocyst body showing no fluorescence. Fig. 10. Anterior end of the sporocyst body after treatment with NaB4 (control). Fluorescence is not visible. b, brain; bc, brain commissure; bf, places of bright fluorescence; bp, bipolar nerve cells; cns, cercarial nervous system; ls, lateral strand; mp, multipolar nerve cell. 
visualised its general topography. In the anterior extremity two concentrations of fluorescent nerve fibres connected by a thin commissure are present (fig. 1). Each concentration (corresponding to a brain ganglion) give rise to nerve fibres running to the anterior end. They are connected by numerous small commissures forming an irregular net (figs. 3, 4, 6). Some fibres of the net with strongly fluorescent endings terminate just below the body surface (figs. 4, 5). In some specimens, at the anterior body tip, a bright fluorescence symetrically distributed was seen (fig. 1). Posteriorly, from neural masses on the lateral side run two distinct strands and on the dorsal and ventral sides the strands are unclear being included in the loop of nerve fibres (figs. 1, 3, 6). At some distance from the anterior end the net disappears. Sometimes the lateral strands extend a little farther. No fluorescence was observed along the body and posterior end of the sporocyst (fig. 9). In some specimens a distinct fluorescence of the perikarya was visualized. Bipolar nerve cells were most frequently seen but multipolar also were observed (figs. 7,8 ). On many whole mounts the cercariae inside the sporocyst body showed fluorescence of the nervous system (figs. 5, 9).

\section{Ultrastructure}

According to our unpublished data the brain of the daughter sporocyst of $D$. pseudosathaceum is composed of paired ganglia connected by commissure containing numerous nerve fibres. Most of the cell bodies of the cerebral ganglia are scattered around the periphery of the ganglion but they are also found in the neuropile area among the nerve fibres. The brain nerve cell bodies have a large centrally placed nucleus and a small amount of cytoplasm. The perikaryon is filled with mitochondria, Golgi complexes, weak developed rough endoplasmic reticulum, ribosomes, microtubules and a variety of vesicles (figs. 11-13). Three morphologically distinct types of vesicles ar found in the cytoplasm of the perikaryon and the neuropile processes (figs. 12-14): (1) small electron-lucent vesicles (axis between 30 and $50 \mathrm{~nm}$ ); (2) dense-core vesicles (axis between 50 and $110 \mathrm{~nm}$ ) which have a clear rim separating the electron dense content from the vesicle membrane; and (3) large electron-lucent vesicles (axis between 60 and $100 \mathrm{~nm})$.

The peripheral nerve systems is not rich in body cells (the same picture showed histofluorescence) and consist mainly of nerve processes lying under the muscle layer or among the contractile parts of muscle cells individually or in small concentrations (figs. 15, 16). The cytoplasm of these processes contain two types of vesicles: small electronlucent, and vesicles with moderate and dense-core (fig. 16). The sensory ending showed in the dendrite two type of vesicles: large oval and sphaeroid electron-lucent vesicles, and dense-core vesicles (figs. 17-20).

\section{DISCUSSION}

The histofluorescence SPG method visualised a general topography of the aminergic system of the D. pseudospathaceum daughter sporocyst. The comparison with cholinergic ones described by Niewiadomska and Moczon (1990) pointed out a similar picture of localization. The green fluorescence which was observed in D. pseudospathaceum sporocysts indicate the presence of catecholamines which were demonstrated in hermaphroditic and parthenogenetic generations of some Digenea species (see discussion Shishov et al., 1987). The lack of yellow fluorescence may be interpreted as indicating a very low amount of indolamines (mainly serotonine) as was shown by Reuter et al. (1980) for the free living turbellarian, Microstomum lineare.

The ultrastructural picture of the nervous system showed vesicles of three different types. Two of them, namely small electron-lucent and dense-core can be morphologically determined as cholinergic and catecholaminergic, respectively. In the daughter spoocyst of $D$. pseudospathaceum the nervous system stains positively for cholinesterase (Niewiadomska and Moczoń, 1990) and the first type of vesicles resembles the vesicles from acetylcholinesterase containing planarian nerves (Czubaj, 1979) or monogenean Gastrocotyle trachuri (Shaw, 1982). Thus these vesicles in D. pseudospathaceum sporocyst may contain acetylcholine although similar vesicles are known to contain other transmitters in other invertebrate (e. g. Botham et al., 1979).

The dense-core vesicles of platyhelminths are regarded as a storage sites of biogenic amines (Reuter et al., 1980; Dei-Cas et al., 1980; Trawicki et al., 1988). In the D. pseudospathaceum sporocyst the distribution of fluorescing cells and fibres correspond with the ultrastructural findings of neurons containing dense-core vesicles.

The third type of vesicles-large electron-lucent-are connected with sensory endings. They were visible in the receptive part of the dendrite, and externally between the cilium an collar of examined sporocyst species (unpublished data) and in Notocotylus attenuatus rediae (Czubaj and Niewiadomska, 1988). The presence of large electron-lucent and dense-core vesicles in the dendrite of sensory cell may be interpreted either as vesicles of different chemical nature, or one population of vesicles at different stages of development. It is possible that the contents of these vesicles take part in a chemoreceptive function of sensory cells.

Both histofluorescence and ultrastructural methods confirm the presence of an aminergic nervous system in the daughter sporocyst of $D$. pseudospathaceum besides the cholinergic one described by Niewiadomska and Moczoń (1990). Neurotransmitters of both the systems play the basic role in neurophysiology of trematodes. Catecholamines and serotonine has been suggested as a possible excitatory, and acetylcholine as inhibitory transmitters (Sukhdeo and Mettrick, 1987).

The aminergic nervous system, the same as cholinergic, 

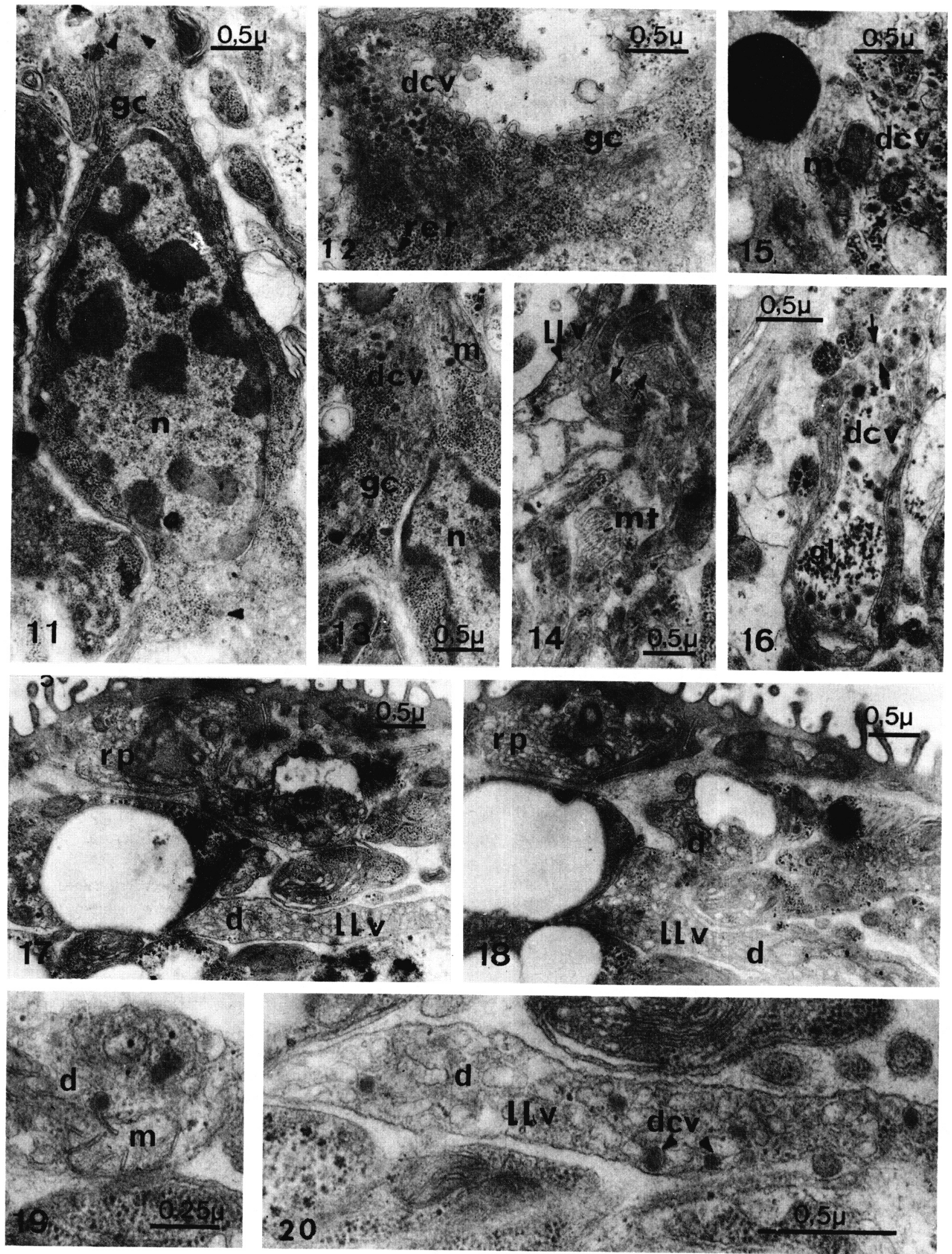

FIGs. 11-20. - Ultrastructure of the nervous system of the daughter sporocyst of Diplostomum pseudospathaceum. Fig. 11. Perikaryon of the brain nerve cell with vesicles (arrowheads). Figs. 12-13. Parts of the brain nerve cell. Fig. 14. Brain neuropile. Figs. 15-16. Parts of nervous cell in peripheral nervous system (15) and nerve process (16) lying below the muscle layer. Figs. 17-20. Successive profiles of the sensory cell. Figs. 19 and 20 show enlarged details of sensory cell dendrite. d, dendrite; dcv, dense-core vesicles; gc, Golgi complexes; gl, glycogen; llv, large lucent vesicles; $\mathrm{m}$, mitochondrion; mc, muscle; mt, microtubules; n, nucleus; r, ribosomes; rer, roughendoplasmic reticulum; rp, receptive part of sensory cell; arrows, small lucent vesicles. 
does not reflect the typical orthogon of hermaphroditic generation (see Niewiadomska and Moczoń, 1982, 1984, 1987). The latter consists of the paired cephalic ganglia connected by the commissure and three pairs of the nerve trunks (of which ventral one are most developed) connected by numerous commissures. Perhaps one could look for some similarity with the nervous system of some « Turbellaria " as such features as net-like structure, the site under the tegument (between the cytons and muscle cells), and the limitation to the anterior sporocyst tip, would be interpreted as primitive. It corresponds also with our observations showing the presence of both cholinergic and aminergic vesicles in one nerve cell-the feature characteristic for Catenulida (Moraczewski et al., 1977) the free-living group having a primitive phylogenetic status (Ehlers, 1988).

\section{REFERENCES}

Bennet J. L., Gianutsos G. : Distribution of catecholamines in immature Fasciola hepatica: A histochemical and biochemical study. Int. J. Parasitol., 1977, 7, 221-225.

Botham R. P., Beadle D. J., Hart R. J., Potter C., Wilson R. G. : Glutamine uptake after stimulation-induced depletion of vesicle numbers of neuromuscular junctions of Locusta migratoria L. Cell Tissue Res., 1979, 203, 379-386.

Chou T.-C. T., Bennet J., Bueding F. : Occurrence and concentrations of biogenic amines in Trematodes. J. Parasitol., 1972, $58,1098-1102$.

Choubisa S. L. : Distribution on non-specific esterases in larval digeneans with a note on morphology of nervous system. Indian J. Exp. Biol., 1989, 27, 32-37.

Corrodi H., Hillarp N. A., Jonsson G. : Fluorescence method for the histochemical demonstration of monoamines. 3. Sodium borohydride reduction of the fluorescent compounds as a specificity test. J. Histochem. Cytochem., 1964, 12, 582-586.

Czubaj A. : Ultrastructural distribution of AChE in Catenula leptocephala (Nuttycombe, 1956). Histochemistry, 1979, 61, 189-198.

Czubaj A., Niewiadomska K. : Types of sensory cells in Notocotylus attenuatus ( $\left.\mathrm{Rud}_{0}, 1809\right)$ rediae (Digenea, Notocotylidae). Parasitol. Res., 1988, 74, 243-249.

Dei-Cas E., Dhainaut-Courtois N., Vernes A. : Contribution à l'étude du système nerveux des formes adultes et larvaires de Schistosoma mansoni Sambon, 1907 (Trematoda, Digenea). I. Aspects morphologiques : anatomie, histologie et ultrastructure chez la forme adulte. Ann. Parasitol. Hum. Comp., 1980, $55,69-86$.

De la Torre J. C., Surgeon J. W. : A methodological approach to rapid and sensitive monoamine fluorescence using a modified glyoxylic acid techniques: the SPG method. Histochemistry, 1976, 49, 81-93.

DiConza J. J., Basch P. F. : Histochemical demonstration of acetylcholinesterase in sporocysts of Schistosoma mansoni (Trematoda). Parasitology, 1975, 71, 305-310.

Ehlers U. : Das Phylogenetische System der Plathelminthes. G. Fischer, Stuttgart-New York, 1985.
Fairweather I., Maule A. G., Mitchell S. H., Johnston C. F., Halton D. W. : Immunocytochemical demonstration of 5-hydroxytryptamine (serotonin) in the nervous system of the liver fluke, Fasciola hepatica (Trematoda, Digenea). Parasitol. Res., 1987, 73, 255-258.

Fuxe K. : Evidence for the existence of monoamine neurons in the central nervous system. III. The monoamine nerve terminal. Z. Zellforsch., 1965, 65, 573-569.

Machado C. R. S., Machado A. B. M., Pellegrino J. : Catecholamine-containing neurons in Schistosoma mansoni. Z. Zellforsch., 1972, 124, 230-237.

Matthews B. F. : Cercaria vaullegeardi Pelseneer, 1906 (Digenea, Hemiuridae); the daughter sporocyst and emergence of the cercaria. Parasitology, 1980, 81, 61-69.

Moraczewski J., Czubaj A., Bakowska J. : Organization and ultrastructure of the nervous system in Catenulida (Turbellaria). Zoomorphologie, 1977, 87, 87-95.

Nezlin L. P., Rybakov A. V. : Histochemical study of nervous system of trematoda cercariae (in Russian). J. Gen. Biol., 1988, $49,695-703$

Niewiadomska K., Moczon T. : The nervous system of Diplostomum pseudospathaceum Niewiadomska (Digenea, Diplostomatidae). I. Nervous system and chaetotaxy in cercaria. Z. Parasitenkd., 1982, 68, 295-304.

Niewiadomska K., Moczoń T. : The nervous system of Diplostomum pseudospathaceum Niewiadomska, 1984 (Digenea, Diplostomatidae). II. Structure and development of the nervous system in metacercaria. Z. Parasitenkd., 1984, 70, 537-548.

Niewiadomska K., Moczoń T. : The nervous system of Diplostomum pseudospathaceum Niewiadomska, 1984 (Digenea, Diplostomatidae). III. Structure of the nervous system in the adult stage. Parasitol. Res., 1987, 73, 46-49.

Niewiadomska K., Moczoń T. : The nervous system of Diplostomum pseudospathaceum Niewiadomska, 1984 (Trematoda, Diplostomidae). IV. Nervous system and distribution of sensilla in the daughter sporocyst. Parasitol. Res., 1990, 76 635-637.

Reuter M., Wikgren M., Palmberg I. : The nervous system of Microstomum lineare (Turbellaria, Macrostomidae). I. A fluorescence and electron microscopic study. Cell Tissue Res., 1980, $211,31-40$.

Shaw M. K. : The fine structure of the brain of Gastrocotyle trachuri (Monogenea: Platyhelminthes). Cell Tissue Res., 1982, 226, 449-460.

Shishov B., Kanev I. : Aminergic elements in the nervous system of echinostomatids and philophthalmids (in Russian). Parazitologiya, 1986, 20, 46-52.

Shishov B. A., Lyukshina L. M., Scherbakova M. A. : Constancy and variability of aminergic nerve cells at different stages of life cycle of Fasciola hepatica parasitic trematoda (in Russian). J. Gen. Biol., 1987, 48, 124-133.

Sukhdeo M. V. K., Mettrick D. F. : Parasite behaviour: understanding platyhelminth responses. Adv. Parasitol., 1987, 26, 73-144.

Théron A., Fournier A. : Mise en évidence de structures nerveuses dans le sporocyste-fils du Trématode Schistosoma mansoni. C. $R$. Acad. Sci. Paris, 1982, 294, 365-369.

Trawicki W., Czubaj A., Moraczewski J. : The brain ultrastructure of Dendrocoelum lacteum (O. F. Miller). Progr. Zool., 1988, $36,195-200$. 